\title{
Experimental investigation on shear strength properties of interface between backfill and rock
}

\author{
Guangsheng Liu \\ BGRIMM Technology Group, Beijing, China \\ Weilv Wu \\ Beijing General Research Institute of Mining and Metallurgy, Beijing, China \\ Lijie Guo \& Xiaocong Yang \\ BGRIMM Technology Group, Beijing, China \\ Zhihong Zhang \\ College of Architecture and Civil Engineering, Beijing University of Technology, Beijing, China
}

SUMMARY: Direct shear tests were carried out with planar interfaces between cemented backfill and rock to obtain cohesion and friction angle. Triaxial compressive tests with the same backfill were used to reveal proportions of shear parameters between interface and backfill. Nonplanar interfaces with different roughness were shear tested for further comparison. A constitutive model for interface was modified based on Mohr Coulomb criterion, which could used to investigate interaction between backfill and rock mass. Numerical simulated shear stress strain were used to validate the model.

Keywords: Backfill, Interface, Shear test, Roughness, Constitutive model

\section{INTRODUCTION}

With increasing requirements on mine safety and environment protection, mining with backfill has been widely used in underground mines worldwide. Stability of backfill in mine stopes is an important factor contributing to the safe mining, especially for the large scale and high efficiency stage open stoping with subsequent backfill mining method. After excavating secondary stopes, stability of exposed cemented backfill in primary stopes will affect not only mining safety, ore recovery and dilution rate, but also mining costs as numerous cement has to be added to the cemented backfill in primary stopes to achieve the stable selfstanding.

Investigation on backfill stability relies on a reasonable evaluation of its stress distribution. As early as 1943, Tezaghi proposed that due to arching effect, actual vertical pressure at the bottom of soil was much smaller than the self-weight of overlying soil. Aubertin et al. (2003) introduced the arching effect from soil mechanics to mining with backfill to analyse the stress distribution of uncemented backfill in vertical narrow stopes. Li (2005) proposed a three dimensional analytical model for the stress distribution of backfill in vertical stopes and analysed influences from stope dimensions and backfill strength properties. But the model is mainly suitable for stress calculations of uncemented backfill. Liu (2019) further modified the 
three dimensional analytical model which could be used for arching stress evaluation of the cemented backfill with practical values of cohesion.

Stress distribution is also the basis for required strength design of the backfill in mining. Mitchell (1989) proposed an analytical model to evaluate strength requirement of backfill in mine stopes, in which interface cohesion between side rock walls and backfill is emphasised. Li (2013) and Liu et al. (2018) extended the analytical models for the backfill strength requirements based on Mitchell method (1989), in which strength parameters of the interfaces between backfill and rock walls are key influential factors.

Liu et al. $(2016,2017)$ utilised numerical methods to investigate necessity of considering interface element between backfill and rock for better simulation of backfill stress distribution. It was found that when interface strength equals to the backfill, there is no difference on backfill stress in numerical models whether to consider interface element or not. However, when interface strength is lower than the backfill, the addition of interface element has significant influences on backfill stress, and the stress distribution is mainly controlled by the interface rather than the backfill.

To sum up, it can be seen that the interfaces between backfill and rock mass controls the backfill stress distribution, which will further affect backfill strength requirement design, thus determine the balance of mining safety and costs. Therefore, it is necessary to investigate the mechanical parameters of interface between backfill and rock.

Direct shear test on the fill-rock interface is an important method to obtain its mechanical characteristics. Up to now, Manaras (2009), Manars et al. (2011), Nasir and Fall $(2008,2010)$, and Koupouli et al. $(2016,2017)$ have carried out exploratory tests of interfaces. But there are some differences of influencing factors in these research, and some opposite conclusions.

Manaras (2009) referred to joint roughness coefficient (JRC) from rock mechanics to prepare backfill-rock interface samples for direct shear tests. Effects from curing age, cement content of backfill and interface roughness on shear strength of interfaces were studied.

Nasir and Fall $(2008,2010)$ used silica sand to replace mine tailings to prepare interface samples with different hard materials (concrete, brick, rock). The results show the friction angle and cohesion along interfaces increase slightly with the increase of curing age within 28 days. When curing temperature increases from $2{ }^{\circ} \mathrm{C}$ to $20^{\circ} \mathrm{C}$ and $30{ }^{\circ} \mathrm{C}$, the friction angle and cohesion of interfaces increase. The friction angle along interfaces is about 0.6 to 1.0 times of the friction angle of corresponding backfill, but no clear proportional relationship for cohesion.

Koupouli et al. (2016, 2017) used different lithologic materials (marble, shale) as hard materials, and prepared interface samples with unclassified tailings and cement $(2.3 \%$ and $8.2 \%$ for cement content). After curing 3 to 7 days, direct shear tests were carried out with the interface samples. It concluded that the friction angle along interface is larger than the friction angle of the corresponding backfill, while interface cohesion is smaller than the backfill. This conclusion is different with the conclusions of Fall and Nasir (2010).

From above, it can be seen that there is not a complete consensus on the shear strength properties of interface between backfill and rock. However, in practical mining with backfill, interface strength parameters (friction angle and cohesion) and their relationships with corresponding backfill have significant influences on stress distribution and strength requirement design of the backfill. Therefore, it is necessary to investigate the shear properties along the interface between backfill and rock mass.

\section{DIRECT SHEAR TEST ON PLANAR INTERFACE}

Planar interface samples were prepared with backfill on the top and rock at the bottom. Granite was selected as rock material with size of length $150 \mathrm{~mm}$, width $150 \mathrm{~mm}$ and height $102 \mathrm{~mm}$. Acrylic plates was used to build the mould surrounding bottom rock and forming the same volume of space on the top for pouring backfill slurry, showing in Figure 1(a). 

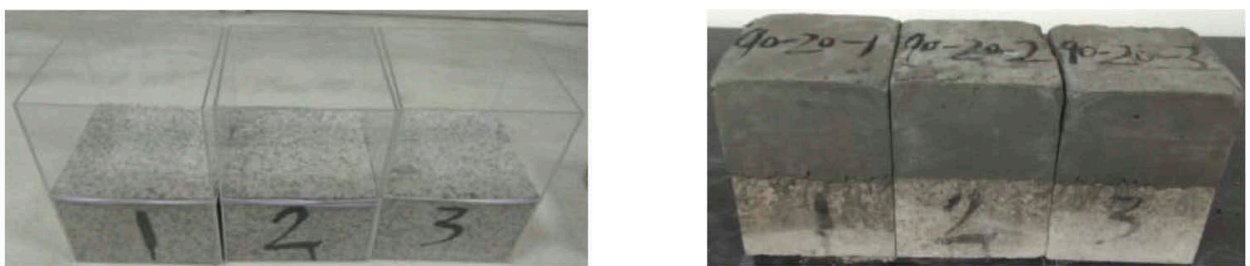

(a) Typical moulds to prepare interface samples and cured planar interface samples

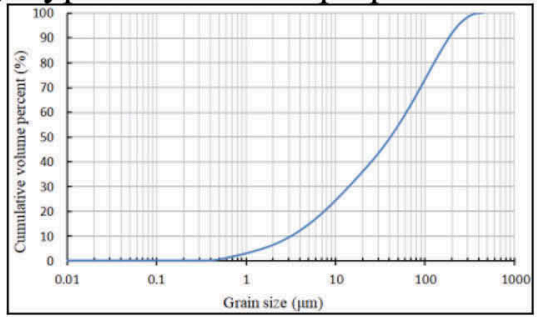

(b) Particle size distribution of tailings

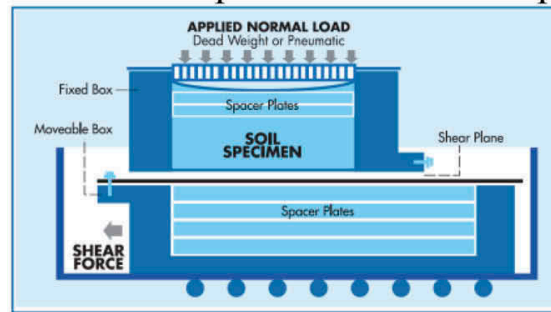

(c) Schematic of interface shear box

Figure 1. Planar interface preparation and direct shear test device.

Backfill was mixed with classified tailings from a nickel mine of China and ordinary Portland cement. The particle size distribution of tailings is shown in Figure 1(b). The density of backfill slurry was fixed to $72 \%$, and cement contents (solid mass percentage) were set to $20 \%$, $9.1 \%$ and $4.76 \%$ respectively. The curing age is 7 and 28 days in the curing room where temperature was fixed to $20 \pm 0.5 \%$ and relative humidity $95 \pm 5 \%$.

A large scale interface shear device produced by Durham Geo Slope Indicator following ASTM D 5321, D 6243 was modified to carry out direct shear tests with interface samples. The vertical pressure applied perpendicular to the interface ranges from $50 \mathrm{kPa}$ to $500 \mathrm{kPa}$.

After a series of direct shear tests on planar interface samples between backfill and rock, typical curves illustrating shear stress changes with horizontal displacement are given in Figure 2. It
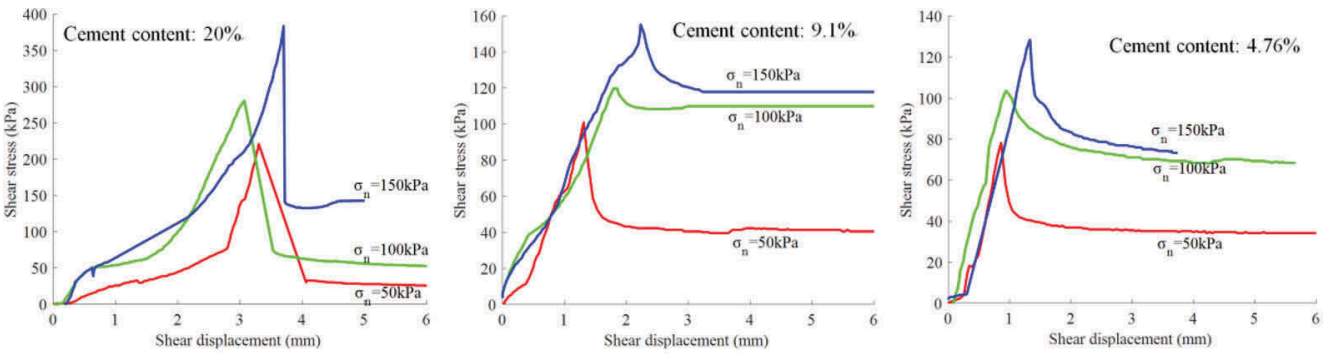

(a) curing 7 days
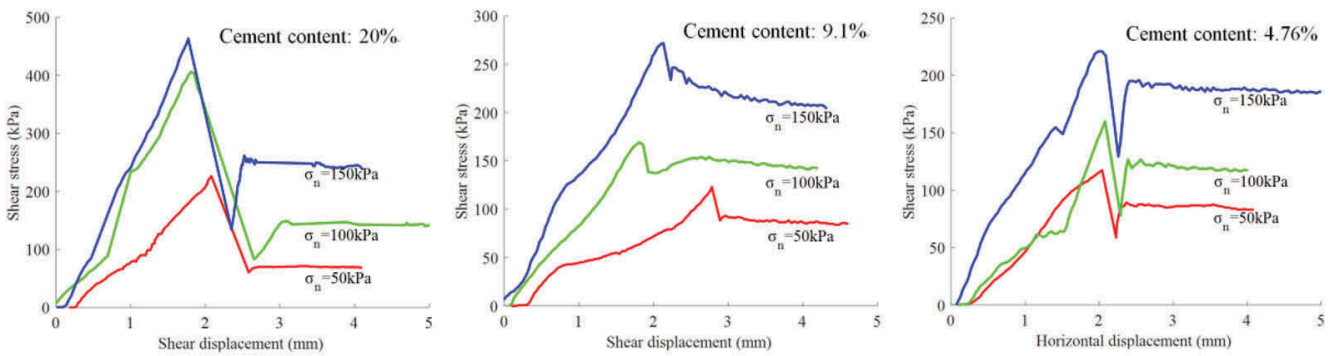

(b) curing 28 days

Figure 2. Variations of shear stress along with horizontal displacement for planar interface samples. 
also shows the variations along with cement contents and normal stresses perpendicular to the interface under different curing days.

It can be seen from the Figure 2 that:

(1) The curves typically contain four parts with the increase of horizontal shear displacement, including the first pore compaction stage, the stage of straight climb for shear strength to a peak point, the stage of quick fallen of shear strength after peak point, and the last stage that residual strength keeps constant with steady increase of displacement.

(2) Both peak shear strength and residual shear strength increase with the increase of normal stress perpendicular to the interface at the same cement content and curing age.

(3) Under the same curing age and vertical stress, with the increase of cement content, the peak shear strength increased significantly, but no significant differences for the residual shear strength with different cement content.

(4) With the increase of curing age, the peak shear strength of interfaces at the same cement content increased significantly, and the residual shear strength increased slightly.

(5) Under the condition of low normal stress, the shear stress curves show significant stress drop after peak point, leading to the residual shear stress is much lower than the peak shear stress.

(6) Before reaching the peak point, the shear strength is mainly composed of adhesive strength and internal friction strength. But after the peak point, there is almost no adhesive cohesion along interface, remaining frictional strength along the interface.

The tested shear strength of interfaces between backfill and rock shown in Figure 2 was further fitted with Mohr Coulomb criterion, i.e. $\tau_{\mathrm{p}}=c_{\mathrm{p}}+\sigma_{\mathrm{np}} \times \tan \phi_{p}$ where $\tau_{\mathrm{p}}(\mathrm{kPa})$ is the peak shear strength and $\sigma_{\text {np }}(\mathrm{kPa})$ is the normal stress perpendicular to the planar interfaces. And then the planar interface cohesion $c_{\mathrm{p}}$ and internal friction angle $\phi_{p}$ could be obtained, as shown in Table 1.

It can be seen from the Table 1 that:

(1) With the increase of cement content, both the cohesion $c_{\mathrm{p}}$ and internal friction angle $\phi_{\mathrm{p}}$ of the planar interface increased significantly at the same curing days.

(2) With the increase of curing age from 7 to 28 days, the cohesion $c_{\mathrm{p}}$ and internal friction angle $\phi_{\mathrm{p}}$ of the planar interface increased slightly at the same cement content. And with the increase of the cement content, the magnitudes for the increasement of interface cohesion and friction angles will be enlarged.

\section{DIRECT SHEAR TEST ON NONPLANAR INTERFACE}

Nonplanar interface samples were prepared with the same backfill recipes, slurry casting method and direct shear test procedures. But before backfill slurry pouring, the upper surface of the rock material were cut to regular teeth to represent different roughness values of the interface, as shown in Figure 3. The roughness is quantified by angle $\alpha \in\left(0^{\circ}, 90^{\circ}\right)$ of each tooth. The bigger for angle $\alpha$, the larger for quantified interface roughness between backfill and rock.

Table 1. Planar interface cohesion $c$ and internal friction angle $\phi$ calculated with shear test results.

\begin{tabular}{ccllll}
\hline $\begin{array}{l}\text { Binder } \\
\text { content }\end{array}$ & Curing days & Linear fitting formula & $\begin{array}{l}\text { Correlation } \\
\text { coefficient }\end{array}$ & $\begin{array}{l}\text { Cohesion } \\
c_{\mathrm{p}}(\mathrm{kPa})\end{array}$ & $\begin{array}{l}\text { Internal friction } \\
\text { angle } \phi_{\mathrm{p}}\left({ }^{\circ}\right)\end{array}$ \\
\hline $20 \%$ & \multirow{2}{*}{$\tau_{\mathrm{p}}=95.3+0.78 \times \sigma_{\mathrm{np}}$} & 0.918 & 95.3 & 38 \\
$9.1 \%$ & 7 & $\tau_{\mathrm{p}}=73.8+0.54 \times \sigma_{\mathrm{np}}$ & 0.998 & 73.8 & 28.5 \\
$4.76 \%$ & $\tau_{\mathrm{p}}=53+0.50 \times \sigma_{\mathrm{np}}$ & 1 & 53 & 26.7 \\
$20 \%$ & & $\tau_{\mathrm{p}}=162.1+1.04 \times \sigma_{\mathrm{np}}$ & 0.908 & 162.1 & 46 \\
$9.1 \%$ & 28 & $\tau_{\mathrm{p}}=80.1+0.58 \times \sigma_{\mathrm{np}}$ & 0.920 & 80.1 & 30.1 \\
$4.76 \%$ & $\tau_{\mathrm{p}}=62.5+0.52 \times \sigma_{\mathrm{np}}$ & 0.989 & 62.5 & 27.4 \\
\hline
\end{tabular}


The teeth angle was set to $10^{\circ}, 30^{\circ}, 45^{\circ}, 60^{\circ}$ respectively to prepare the rock base with different interface roughness, and then the backfill slurry with different cement contents was poured to the upper volume and cured for 28 days to carry out the direct shear tests. The direction of applied shear force is perpendicular to the direction of teeth alignment, not along with the groove. When the teeth angle $\alpha$ equal to $0^{\circ}$, it will come to the planar interface.

After a series of direct shear tests on the nonplanar interface samples between backfill and rock, the relationships between peak shear strength $\tau_{\mathrm{r}}$ and the normal stress $\sigma_{\mathrm{nr}}$ acting on equivalent horizontal contact surface were obtained. Then the equivalent cohesion $c_{\mathrm{r}}$ and interface friction angle $\phi_{\mathrm{r}}$ along the rough interface were calculated with linear fitting method based on Mohr Coulomb criterion varying with the teeth angle $\alpha$.

Figure 4 shows relationships of peak shear strength $\tau_{\mathrm{r}}$, equivalent cohesion $c_{\mathrm{r}}$ and internal friction angle $\phi_{\mathrm{r}}$ of rough nonplanar interface with teeth angle $\alpha$. The density of backfill slurry is also fixed to $72 \%$ and the cement content showed in Figure 4 is $9.1 \%$.

It can be seen from the Figure 4 that:

(1) The peak shear strength increase linearly with the increase of equivalent normal stress acting on the nonplanar interface from $50 \mathrm{kPa}$ to $300 \mathrm{kPa}$.

(2) When the teeth angle is smaller than $30^{\circ}$, the peak shear strength increases with the increase of the teeth angle under the same normal stress.

(3) When the teeth angle is bigger than $30^{\circ}$, the peak shear strength increases very slightly under the same normal stress. This is corresponded with the simulation results of Liu et al. (2016) that when the nonplanar interface becomes rough enough, the potential shear sliding will move from along interface to inside the backfill, which will make the shear stress determined by the backfill strength.

(4) The cohesion of the nonplanar interface increases almost linearly with the increase of the teeth angle. But, the friction angle of the nonplanar interface firstly increases and then decreases with the increase of the teeth angle, turning at the teeth angle of $30^{\circ}$.
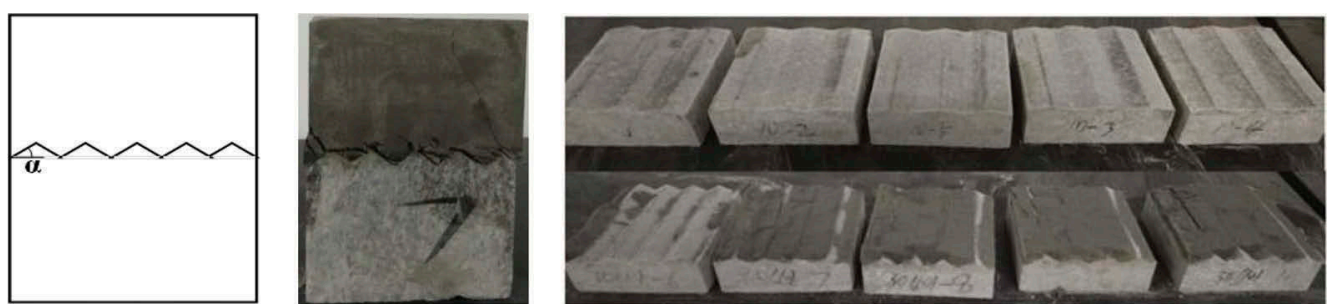

Figure 3. Nonplanar interface with different roughness and typical shear tested samples.
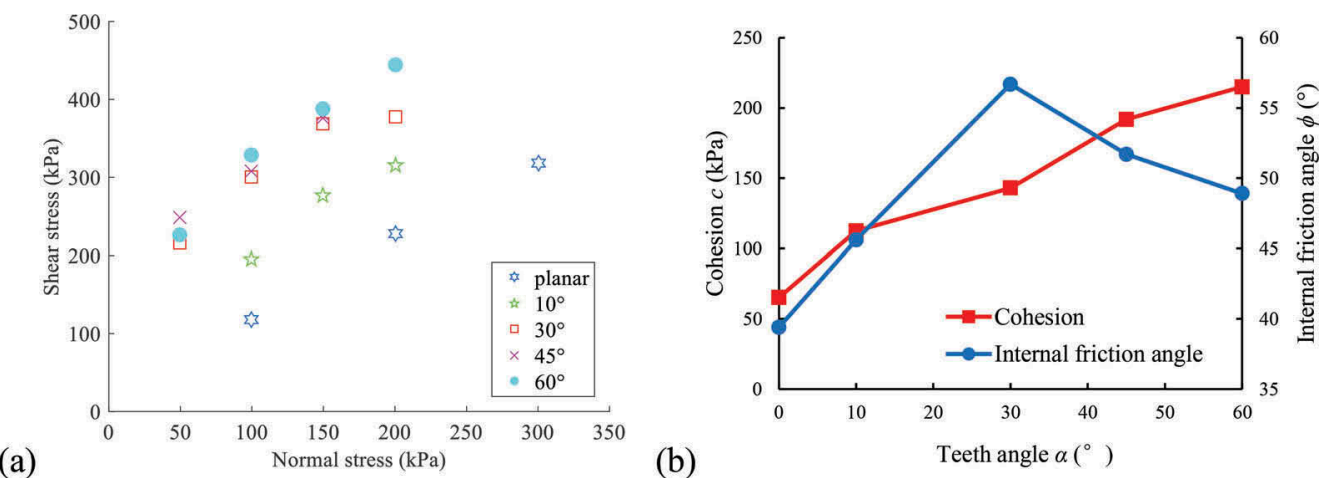

Figure 4. Relationships of shear strength, cohesion and friction angle of rough interface with teeth angle. 


\section{COMPARISON OF INTERFACE AND BACKFILL SHEAR STRENGTH}

The relationships between the interface and the corresponding backfill are important to backfill stress and strength requirement evaluation in mine stopes, because the ratios of cohesion and internal friction angle between interface and backfill are usually adopted in most previous studies (Mitchell 1989, Li et al. 2005, Liu et al. 2018).

Along with the planar and nonplanar interface samples between backfill and rock, cylindrical samples of the backfill with the same recipe were casted and cured for triaxial compressive tests, by which the cohesion $c_{0}$ and internal friction angle $\phi_{0}$ of the corresponding backfill could be obtained. Figure 5 shows a part of the cured cylindrical backfill samples and the typical testing procedure with soil triaxial apparatus.

After the triaxial compressive tests of cylindrical backfill samples, the cohesion $c_{0}$ and friction angle $\phi_{0}$ of the backfill with different cement contents and cured for 28 days are listed in Table 2. Meanwhile, the cohesion $c_{\mathrm{p}}$ and friction angle $\phi_{\mathrm{p}}$ of the planar interfaces, and the cohesion $c_{\mathrm{r}}$ and friction angle $\phi_{\mathrm{r}}$ of the rough nonplanar interfaces (teeth angle $\alpha=60^{\circ}$ ) are also given in Table 2 for comparison.

It can be seen from the Table 2 that:

(1) With the increase of cement content, all values of the cohesion and friction angle of the backfill, planar and nonplanar interfaces increase. This result partly responds to the controversy of whether the backfill friction angle is insensitive to the cement content but mostly determined by the particle size distribution of aggregate (unclassified tailings here).

(2) The backfill cohesion is always bigger than the interface cohesion, but the backfill friction angle is always smaller than the corresponding interface friction angle (planar and nonplanar). This result is similar to the conclusions shown in Koupouli et al. $(2016,2017)$.

(3) The cohesion $c_{\mathrm{p}}$ of planar interfaces is much smaller than the backfill cohesion $c_{0}$, and the increase of cement content will enlarge the differences. However the cohesion $c_{\mathrm{r}}$ of nonplanar interfaces (teeth angle $\alpha=60^{\circ}$ ) is slightly smaller but very close to the corresponding backfill cohesion $c_{0}$ at different cement contents. It indicates that the increase of roughness for the interface will increase the interface cohesion, but with the backfill cohesion as the upper limit.

(4) The friction angle $\phi_{\mathrm{p}}$ of planar interfaces is slightly bigger than the backfill friction angle $\phi_{0}$. And with the increase of interface roughness, the differences will be enlarged. The friction angle $\phi_{\mathrm{r}}$ of nonplanar interfaces is much bigger than the backfill friction angle $\phi_{0}$. This is because the frictional resistance along interface is composed of combined action of backfill and rock. The contributions from rock with much higher friction angle makes the equivalent fricton angle of interface increase obviously. Besides, the shear dilatancy effect along raised teeth of nonplanar interfaces helps to expand the frictional resistance and lead to a higher equivalent fricton angle.
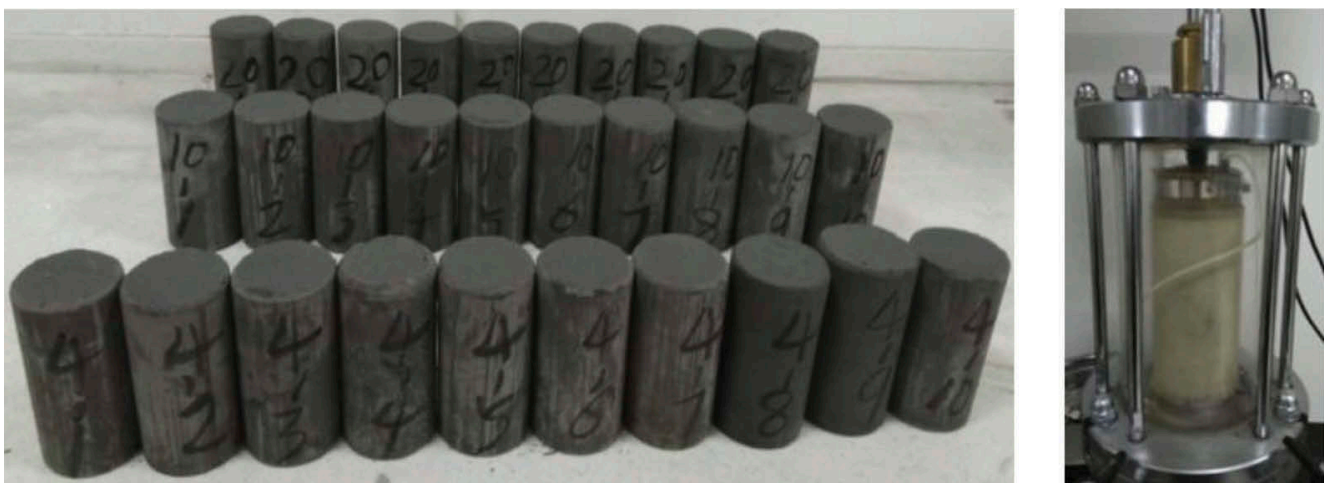

Figure 5. Casted cylindrical backfill samples for triaxial compressive tests. 
Table 2. Comparison of cohesion and friction angle of backfill with planar and nonplanar interfaces.

\begin{tabular}{lllllll}
\hline & \multicolumn{2}{l}{$\begin{array}{l}\text { Triaxial compressive tests of } \\
\text { cylindrical backfill }\end{array}$} & $\begin{array}{l}\text { Direct shear tests of } \\
\text { planar interface }\end{array}$ & \multicolumn{2}{l}{$\begin{array}{l}\text { Direct shear tests of rough non- } \\
\text { planar interface }\left(\alpha=0^{\circ}\right)\end{array}$} \\
\cline { 2 - 7 } $\begin{array}{l}\text { Binder } \\
\text { content }\end{array}$ & $\begin{array}{l}\text { cohesion } c_{0} \\
(\mathrm{kPa})\end{array}$ & $\begin{array}{l}\text { friction } \\
\text { angle } \phi_{0}\left({ }^{\circ}\right)\end{array}$ & $\begin{array}{l}\text { cohesion } c_{\mathrm{p}} \\
(\mathrm{kPa})\end{array}$ & $\begin{array}{l}\text { friction } \\
\text { angle } \phi_{\mathrm{p}}\left({ }^{\circ}\right)\end{array}$ & $\begin{array}{l}\text { cohesion } c_{\mathrm{r}}(\mathrm{kPa}) \\
\text { friction } \\
\text { angle } \phi_{\mathrm{r}}\left({ }^{\circ}\right)\end{array}$ \\
\hline $20 \%$ & 718.6 & 31.4 & 162.1 & 46 & 661 & 52.9 \\
$9.1 \%$ & 256.6 & 27.5 & 80.1 & 30.1 & 215 & 48.9 \\
$4.76 \%$ & 155.8 & 26.3 & 62.5 & 27.4 & 125 & 45.3 \\
\hline
\end{tabular}

(5) It is not suitable to separately use ratios of interface cohesion to backfill cohesion and interface friction angle to backfill friction angle at one model to evaluate backfill stress or strength requirement, because it is not simple proportional relationship for shear strength parameters (cohesion and friction angle) between the interface and the backfill.

\section{MODIFIED SHEAR STRENGTH MODEL FOR INTERFACE}

According to the shear test results for interfaces and triaxial test results for corresponding backfill under 28 curing days, the conversion relations of cohesion $c_{\mathrm{p}}$ and friction angle $\phi_{\mathrm{p}}$ for planar interface compared with cohesion $c_{0}$ and friction angle $\phi_{0}$ for backfill can be seen in equations (1) and (2) respectively.

$$
\begin{aligned}
& c_{p}=0.177 c_{0}+34.798 \\
& \phi_{p}=3.734 \phi_{0}-71.595
\end{aligned}
$$

The conversion relations of cohesion $c_{\mathrm{r}}$ and friction angle $\phi_{\mathrm{r}}$ for rough nonplanar interface compared with cohesion $c_{0}$ and friction angle $\phi_{0}$ for backfill can be seen in equations (3) and (4) respectively.

$$
\begin{aligned}
& c_{r}=0.956 c_{0}-26.893 \\
& \phi_{r}=1.383 \phi_{0}+9.737
\end{aligned}
$$

From the above equations, it can be seen that for planar and nonplanar interfaces, it is not simple proportional relationship for cohesion and friction angle between interface and backfill. And these relations could be utilised to update the analytical models for stress distribution and strength requirement evaluation, e.g. Mitchell (1989), Li et al. (2005), and Liu et al. (2018).

In addition, the classical Mohr Coulomb criterion (i.e. $\tau=c+\sigma_{\mathrm{n}} \times \tan \phi$ where $\tau(\mathrm{kPa})$ is the peak shear strength and $\sigma_{\mathrm{n}}(\mathrm{kPa})$ is the normal stress perpendicular to the failure plane of the material) which is mainly suitable for uniform cohesive materials has been widely used for backfill stress calculation. But there is no consideration about the interface between backfill and rock, and no parameter of interface roughness in the criterion. The shear strength criterion proposed by Barton (1977) for rock joints consider the roughness of failure plane, but there is no consideration of large interface cohesion from cemented backfill in the criterion, and the JCR values characterizing roughness are difficult to measure.

Here, incorporating equations (1) and (2) to the classical Mohr Coulomb criterion, the equation (5) could be obtained for the shear strength of planar interface based on the tested values of cohesion $c_{0}$ and friction angle $\phi_{0}$ of cemented backfill. 


$$
\tau=\sigma_{n} \tan \left(3.734 \phi_{0}-71.595\right)+0.177 c_{0}+34.798
$$

Similarly, incorporating equations (3) and (4) to the classical Mohr Coulomb criterion, the equation (6) could be obtained for the shear strength of rough nonplanar interface (teeth angle $\alpha=60^{\circ}$ ) based on the tested values of cohesion $c_{0}$ and friction angle $\phi_{0}$ of cemented backfill.

$$
\tau=\sigma_{n} \tan \left(1.383 \phi_{0}+9.737\right)+0.956 c_{0}-26.893
$$

Empirical equations (5) and (6) obtained here with data from direct shear tests on interfaces and triaxial compressive tests on backfills could be used for the mechanical analysation of the interfaces between backfill and rock during the evaluation of stress, required strength and stability of cemented backfill in mine stopes.

For the validation of these modified equations based on Mohr Coulomb criterion, a series of numerical modellings were carried out with FLAC3D to simulate the direct shear tests on planar and nonplanar interfaces. The dimensions of the numerical models are corresponding with the fillrock interface samples, and the backfill shear strength properties are based on the triaxial test results (The density of backfill slurry is fixed to $72 \%$ and the cement content is $9.1 \%$ ).

Figure 6 shows the comparisons of peak shear strength of planar and nonplanar (teeth angle $\alpha=60^{\circ}$ ) interfaces at different normal stress perpendicular to the interface.

It can be seen from Figure 6 that the simulated peak shear stress with FLAC3D generally fit well with the tested peak shear stress along with the planar interfaces and nonplanar interfaces (teeth angle $\alpha=60^{\circ}$ ). This demonstrates that modified equations (5) and (6) based on Mohr Coulomb criterion to calculate the peak shear strength for planar and nonplanar interfaces are usable to some extent.

However, it can also be seen in Figure 6 that there are still obvious differences between the simulated and the tested peak stress. This might be caused by the nonlinear deformation of backfill under normal pressure and the different failure modes along interfaces due to shear dilatancy of nonplanar interfaces.

Besides, Figure 6 illustrates that the simulated peak shear stress will gradually flatten under higher normal stress (after $200 \mathrm{kPa}$ ) for nonplanar interfaces (teeth angle $\alpha=60^{\circ}$ ). But the simulated peak shear stress for planar interface show a linear growth with the increase of the normal stress. This linear growth trend also happens for both planar and nonplanar interfaces during the direct shear tests. More tests and analyse should be carried out with nonplanar interface samples in different roughness to understand its differences with corresponding simulated results.

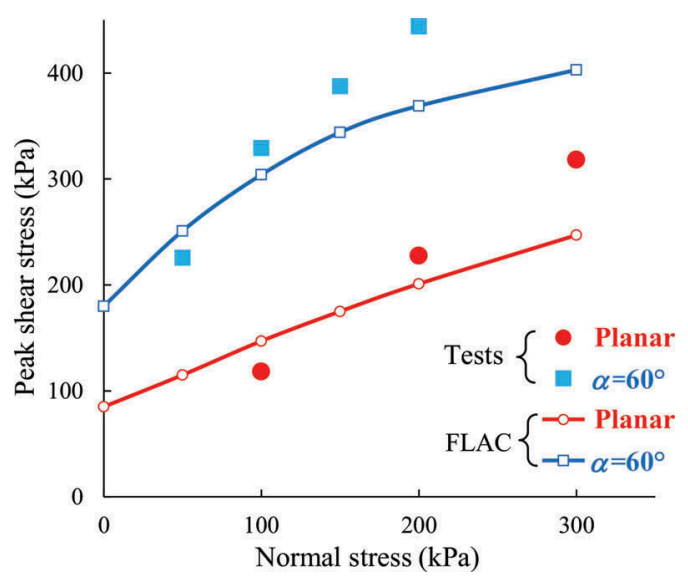

Figure 6. Comparison of tested and simulated peak shear stress along planar and nonplanar interfaces. 


\section{CONCLUSIONS}

In order to investigate shear strength properties of planar and nonplanar interface between backfill and rock, a series of interface samples with different roughness and backfill recipes were prepared and set to direct shear tests. Triaxial compressive tests were carried out to obtain the cohesion and internal friction angle of the corresponding backfill. The relationships about cohesion and internal friction angle between interface and backfill were compared and analysed. The key conclusions in the investigations are summarised bellow:

(1) The tested backfill cohesion is always bigger than the interface cohesion, but the backfill friction angle is always smaller than the corresponding interface friction angle (for conditions of planar and nonplanar interfaces).

(2) The increase of interface roughness will enlarge the interface cohesion and friction angle, but the corresponding backfill cohesion is the upper limit for the increasement of the interface cohesion.

(3) The relationships of cohesion and internal friction angle between interface and corresponding backfill are not simple proportional ratios which had been adopted in most previous studies, but conform to linear correlations.

(4) Empirical linear functions were given to calculate relations of cohesion and friction angle for planar and nonplanar interface compared with cohesion and friction angle for the corresponding backfill, respectively.

(5) New models were proposed based on Mohr Coulomb criterion for the calculations of peak shear strength of planar and nonplanar interface with the tested cohesion and internal friction angle of corresponding backfill. Numerical simulations validated the availability of the new models.

\section{ACKNOWLEDGEMENTS}

Financial supports from the National Natural Science Foundation of China (grant no. 51774040, 51804031) and the Youth Science and Technology Innovation Fund of BGRIMM Technology Group (grant no. QCJ201804) is gratefully acknowledged. Many thanks to the peer reviewers to give constructive suggestions on the paper.

\section{BIBLIOGRAPHY}

Aubertin, M., Li, L., Arnold, S., Belem, T., Bussière, B., Benzaazoua, M. and Simon, R. 2003. Interaction between backfill and rock mass in narrow stopes. [In:] Proceedings of the 12th Panamerican Conference on Soil Mechanics and Geotechnical Engineering, Essen, Germany, 22-26 June.

Barton, N. \& Choubey, V. 1977. The shear strength of rock joints in theory and practice. Journal of Rock Mechanics and Rock Engineers. 10(1-2):1-54.

Fall, M., and Nasir, O. 2010. Mechanical behaviour of the interface between cemented. Geotechnical and Geological Engineering, 28(6):779-790.

Tezaghi, K. 1943. Theoretical Soil Mechanics. John Wiley and Sons: New York, NY.

Li, L., Aubertin, M., and Belem, T. 2005. Formulation of a three dimensional analytical solution to evaluate stresses in backfilled vertical narrow openings. Canadian Geotechnical Journal, 42(6), 1705-1717.

Li, L. 2013. Generalized solution for mining backfill design. International Journal of Geomechanics, 14(3), 04014006.

Liu, G.S., Li, L., Yang, X.C., and Guo, L.J. 2016. A numerical analysis of the stress distribution in backfilled stopes considering nonplanar interfaces between the backfill and rock walls. International Journal of Geotechnical Engineering, 10(3):271-282.

Liu, G.S., Li, L., Yang, X.C., and Guo, L.J. 2017. Numerical Analysis of Stress Distribution in Backfilled Stopes Considering Interfaces between the Backfill and Rock Walls. International Journal of Geomechanics. 17(2): 06016014. 
Liu, G.S., Li, L., Yang, X.C., and Guo, L.J. 2018. Required strength estimation of a cemented backfill with the front wall exposed and back wall pressured. International Journal of Mining and Mineral Engineering, 9(1), 1-20.

Liu, G.S., Yang, X.C. and Guo L.J. 2019. Models of three-dimensional arching stress and strength requirement for the backfill in open stoping with subsequent backfill mining. Journal of China Coal Society, 44(5):1391-1403.(in Chinese)

Manaras, S. 2009. Investigations of backfill-rock mass interface failure mechanisms, M.A.Sc. thesis, Queen's University, Kingston, Ontario, Canada.

Manars, S., De Souza, E. and Archibald, J.F. 2011. Strength behaviour and failure mechanisms of backfill-rock mass interfaces. [In:] Minefill 2011, 10th International Symposium on Mining with Backfill, The Southern African Institute of Mining and Metallurgy, Cape Town, South Africa.

Nasir, O., and Fall, M. 2008. Shear behaviour of cemented pastefill-rock interfaces. Engineering Geology, 101(3/4):146-153.

Koupouli, N.J.F., Belem, T., Rivard, P. and Hervé, E. 2016. Direct shear tests on cemented paste backfill-rock wall and cemented paste backfill-backfill interfaces. Journal of Rock Mechanics and Geotechnical Engineering, 8(4):472-479.

Koupouli, N.J.F., Belem, T. and Rivard, P. 2017. Shear strength between cemented paste backfill and natural rock surface replicas. [In:] Proceedings of the First International Conference on Underground Mining Technology, Australian Centre for Geomechanics, Perth, Australia, 375-385 October. 